\title{
Student Cognition in the Context of a Climate System: Global Warming and Greenhouse Effect
}

\author{
Rif'ati Dina Handayani ${ }^{1}$, Pramudya DA Putra $^{2}$ \\ ${ }^{1}$ Physics Education Department, University of Jember, Indonesia \\ ${ }^{2}$ STEM Education Department, Graduate School of Science Informatics and Technology, Shizuoka University, Japan \\ * Corresponding Author. E-mail: rifati.fkip@unej.ac.id
}

\begin{abstract}
Education needs to emphasize more attention to environmental issues. The school is an active place to provide actual knowledge, skills, attitudes, and behavior towards environmental issues such as global warming dan the greenhouse effect. This study aimed to investigate seventh-grade students' cognition in the context of a climate system. This study was descriptive, involving the collection of qualitative data. These qualitative data were then analyzed for their content inductively to identify concepts and patterns of student responses. This study indicated that students believed that global warming caused by six factors involving the greenhouse effect, depletion of the ozone layer, fossil fuel usage, forest fires, use of chemicals, and industrial air pollution. Also, they convinced six segments of the global warming impacts: ocean, soil, air, plants and animals, humans, and weather and season changes. The student thought about the climate system was substantially linear, where the contribution of human activities caused global warming that finally have an impact on humans themselves.
\end{abstract}

Keywords: student cognition; climate system; global warming; the greenhouse effect

\section{Introduction}

Environmental problems and climate change are not new issues. Climate change is an essential environmental issue facing society as such is a critical environmental education (Stevenson, 2007). Managing climate change issues need to involve all participants globally. Educational policies and curricula are needed to promote climate change strategies, especially adaptation and mitigation through increased knowledge, understanding of the causes and impacts of climate change. In some countries, the implementation of climate change study is carried out at both the formal and non-formal and informal levels. They have undertaken to set a global warning topic into their curricula, including Indonesia. Indonesia is highly vulnerable to climate change, which causes disasters such as floods, landslides, extended droughts, strong winds, and high waves. Threats to climate can even occur in higher intensity and felt by farmers, fishers, coastal, rural, and urban communities. The Indonesian government continues to strive to mobilize all elements of society in addressing climate change issues (Dewi, Hendarti, Matakupan, \& Lisdiyanta, 2012).

According to the Global Education Monitoring (2016), there are 78 national curricula in the world where $55 \%$ used the term of ecology education, and $45 \%$ use the name of environmental education. Environmental education encourages sustainable lifestyles, helps people to prepare themselves, and adapt to all the effects of climate change (Papadimitriou, 2004). Learning environments tend to have either a severe effect or the ability to encourage learning and increasing initiatives to obtain a change in society (Bélanger, 2003).

Climate change is a complex phenomenon (Schreiner, Henriksen, \& Kirkeby Hansen, 2005). The changes cannot be observed in a short time; it took a very long time and on a global scale (Tolppanen \&

How to Cite:

Handayani, R., \& Putra, P. (2019). Student Cognition in the Context of a Climate System: Global Warming and Greenhouse Effect. Momentum: Physics Education Journal, 3(2), 69-77. https://doi.org/10.21067/mpej.v3i2.3739 
Aksela, 2018). United Nations Framework Convention on Climate Change (UNFCCC) defined climate change as a change in the composition of the global atmosphere and natural climate variability in a comparable period caused by human activities either directly or indirectly. The global atmospheric composition is the material composition of the Earth's atmosphere in the form of Greenhouse Gases consisting of Carbon Dioxide, Methane, Nitrogen, etc. Greenhouse Gases are needed to keep the temperature of the earth stable. However, increasing greenhouse gas concentrations make the atmosphere thicker. The thickening of the atmospheric layer causes the increasing amount of geothermal heat trapped in the atmosphere, increasing the earth's temperature, which is called global warming, In short, global warming refers to the rising average global temperature (Svihla \& Linn, 2012). A small change in global energy stability can significantly change the global temperature.

The global emission reduction target will not be achieved if the issue of climate change only becomes a discourse and is discussed at national and international levels (Serafin et al., 1991). Agents of change in the level of education unit had a role in enhancing the capacity of learners in understanding, encouraging to participate in the action controlling climate change by taking into account the ability of students (Ocal, Kisoglu, Alas, \& Gurbuz, 2011). In this case, education must take a role. Education plays a vital role in transforming and creating people to live in more sustainable environments (Dewi et al., 2012). Education needs to emphasize more attention to environmental issues, climate change, and global warming. The school is an active place to provide actual knowledge, skills, attitudes, and behavior towards the environment, including climate change issues, adaptation, and mitigation actions. Schools can help students find out about environmental problems, consequences, and what types of actions must be taken to overcome (Shepardson, Niyogi, Choi, \& Charusombat, 2009). Rajeev Gowda et al. (1997) stated that the school was required to deal with global warming and climate change and to familiarize the learner about the importance of this problem. One effort to express the effect of climate change is taught to students. Increasing student understanding of climate change issues needs to be a concern, so they can actively participate in diminishing the causes and impacts of climate change (Stevenson, 2007).

Academies should be trying to handle these problems as part of their responsibility of accommodating the learner to orient themselves in the global environment. If learning is only to improve careers, then this will be detrimental and harm the environment. Cultivating the actions of controlling climate change in the school environment is an equally important part (Shepardson et al., 2009). Learning about global warming and climate change gives an actual context for studying science through personal and social relationships that future citizens are to expect responsibility for command of the earth (Bélanger, 2003; Shepardson, Niyogi, Roychoudhury, \& Hirsch, 2012). Education about the environment can encourage sustainable student lifestyles, such as reducing waste and increasing the use of public transportation.

The challenges in learning about global warming and climate change are the complexity of the science concept behind climate change (Svihla \& Linn, 2012; Tolppanen \& Aksela, 2018). Some studies showed that pupils' knowledge about climate change is weak and students endure many misconceptions such as ozone depletion and air-polluting contributed to climate change (Andersson \& Wallin, 2000; Svihla \& Linn, 2012) This study aimed to investigate seventh-grade students' cognition in the context of a climate system. The research question in this study was: what are students' cognitions in the context of a climate system: global warming and greenhouse effect?

\section{Method}

This study was conducted at three national secondary schools in the Special Region of Yogyakarta. The school was situated in a modest and rural district. The participants consisted of 135 seventh grade students, 45 students in each school. There were 97 females (71.85\%) and 38 males (28.15\%). The students' age was 13-14 years. The main reason for choosing the seventh-grade student was the Indonesian student 
starts to learn this topic at this level. The participant includes a range of student academic ability low to excellent knowledge. The study was conveyed with limited data about the social, cultural, and educational experiences of the learner and how these might affect their responses.

Data were collected in the natural science classroom as the assessment instrument. The assessment was directed by the teachers before any school on climate change concepts. Complete of the participant finished the test throughout their routinely scheduled. The assessment consisted of four items: 1) The description of global warming and climate change; 2) the cause of global warming; 3 ) the impact of global warming; 4) the understanding of the greenhouse effect. The participant responses are not scored as a "true" or "false," but it was analyzed for the content. The student wrote their answer and drawn their conceptual understanding contain a number of their knowledge that is accomplished with meaning. Students were written language and drawings represent and express their cognition, meaning, interest, motivation, and views (Kress, Jewitt, Ogborn, \& Tsatsarelis, 2014).

This study was descriptive, involving the collection of qualitative data. These qualitative data were then analyzed for the content in an inductive manner to identify concepts and patterns of student responses. The interpretative nature of the assessment required an inductive approach, such as searching for pre-determined patterns, construct a theme from student responses (Johnson \& Christensen, 2013). The qualitative data were arranged into a file folder since a significant amount of information found during the study. All student answers to a particular question were read repeatedly and analyzed in detail to answer the research question. During this process, ideas are formed regarding how to describe participant responses. From the first reading, the essential concept was identified and recognized. The researcher perceived the meant student responded that appropriates about climate system content, particularly for global warming and the greenhouse effect. The critical information from student responses was then organized and interpreted categories initially by creating a table in Microsoft Excel and then corrected for a second reading. This process was arranged to check the data for congestion and reduce irrelevant categories. The last result is a manual, in which heads and examples of answers set the categories. Most of the illustrations were realizing and describing the majority of the student responses. Also, this process of independently developing types provided a degree of triangulation, diminishing bias, and subjectivity, and enhancing the validity (Calderon, 2011; Creswell, 2012).

\section{Results and Discussion}

\subsection{Result}

\subsubsection{The causes of global warming}

Students defined global warming as an increase in the average temperature on earth $(N=120$, $88.89 \%)$. They believed that global warming caused by a broad various environmental harmful behavior such as the greenhouse effect, depletion of the ozone layer, fossil fuel usage, forest fires, use of chemicals, and industrial air pollution (Table 1).

Table 1. The causes of global warming

\begin{tabular}{lll}
\hline Causes factors & Number of responses $(\mathrm{N})$ & \% of the total \\
\hline Burning of fossil fuels & 116 & 85.92 \\
Greenhouse effect & 109 & 80.74 \\
Ozone layer depletion & 88 & 65.19 \\
Deforestation and forest fire & 75 & 55.56 \\
Chemicals & 33 & 24.44 \\
Industries/factories & 66 & 48.89 \\
\hline
\end{tabular}

The majority of students responded that the use of fossil fuel ( $N=116,85.92 \%)$ is the main factor of global warming. Fossil fuels are broadly used by motor vehicles and coal-fired power plants. The 
combustion of fuels raised air pollution and the concentration of carbon dioxide (CO2) and methane ( $\mathrm{CH} 4)$ in the atmosphere.

"The use of fossil fuels that produce carbon dioxide $\left(\mathrm{CO}_{2}\right)$ makes the average global temperature rise" (B1-S38-2).

"The usage of fuel by motor vehicles and industry increases carbon dioxide emissions in the air" (P1S45-2).

Additionally, deforestation and forest burning $(\mathrm{N}=75,55.56 \%)$ are also considered as causes of increasing carbon dioxide and decreasing the amount of oxygen in the atmosphere. They claimed that an increase in carbon dioxide and a decrease in oxygen levels in the atmosphere would cause a greenhouse effect.

"Forest fires raise the number of greenhouse gases, reducing the oxygen concentration in the air" (J1S22-2).

Furthermore, more than half (65.19\%) of the participants responded that the ozone layer depletion and holes are one of the reasons for global warming - the holes in the ozone layer leading to a rise in Ultra Violet (UV) radiation. The ozone layer depletion is increasing the intensity of sunlight that reaches the earth, so the earth is getting warmer. This is in line with research by Österlind (2005) and Andersson and Wallin (2000), where their participants also stated that global warming occurs because of ozone depletion and holes. The student also expressed that the use of spray aerosols containing chlorofluorocarbons (CFCs) caused thinning of the ozone layer and perforated. Actually, CFCs give a small contribution to global warming compared to the burning of fossilized fuels.

"The use of CFCs in aerosol spray perforates the ozone layer, and the incoming sunlight intensity increases make the earth's temperature rises" (P1-S10-2).

"The gas that reduces the ozone layer, driving to a higher temperature" (B1-S44-2).

\subsubsection{The Greenhouse effect}

From the scientific perspective, 75 pupils endured a further scientific understanding of the greenhouse effect. They identified $\mathrm{CO} 2, \mathrm{CH} 4, \mathrm{CFCs}$ as a greenhouse gas, short-wave radiation as being reemitted by the atmosphere and earth's surface. Even those participants did not identify other greenhouse gases such as water vapor.

"Much of the solar radiation is re-reflected to the earth as a result of rising concentrations of greenhouse gases (CO2, CH4, CFCS)" (J1-S15-4).

"Gas pollutant entraps the sun radiation in the atmosphere, thus causing heat" (P1-S25-4).

Generally, students responded that the greenhouse effect is the process of solar radiation that goes to the earth's surface, one-third is reflected into space, and in part is absorbed by the atmosphere and the earth's surface. The earth re-emits the absorbed heat in the form of shortwave radiation, which absorbed by certain gases in the atmosphere, such as $\mathrm{CO} 2, \mathrm{CH} 4, \mathrm{CFC}$. Since these gases re-radiate heat to the earth in all directions, it causes the earth's temperature to rise. Here some examples of students drawing about the greenhouse effect. 


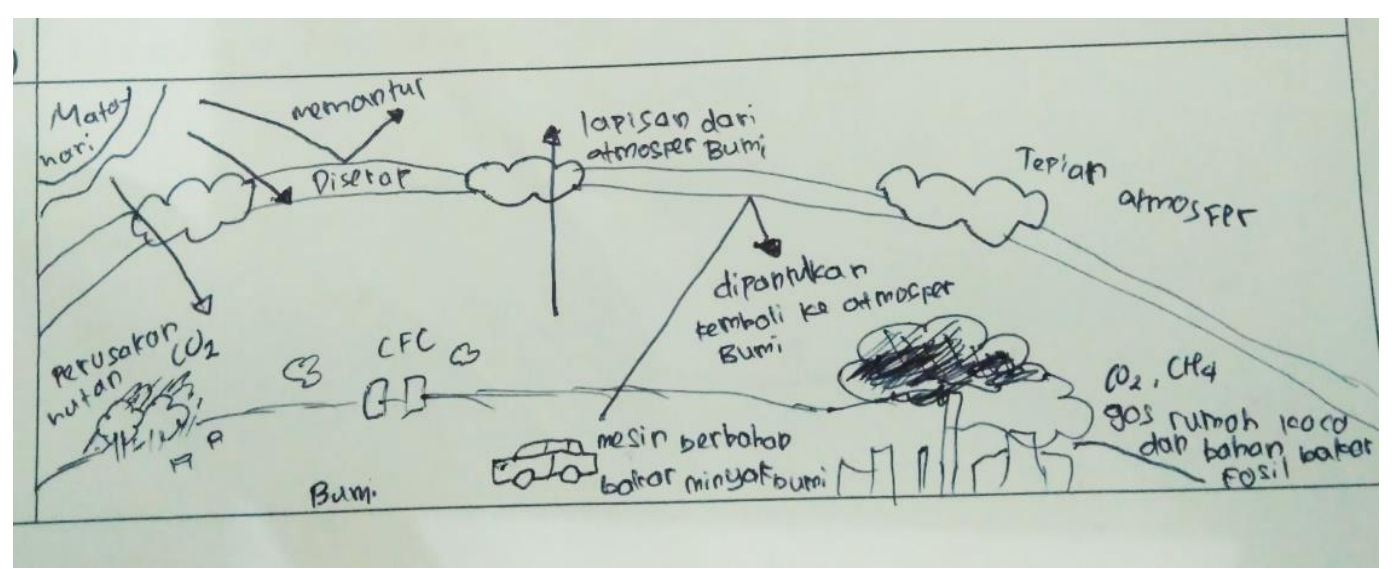

Figure 1. Example student sketches representing the source of greenhouse gases and radiative energy as "sun rays."

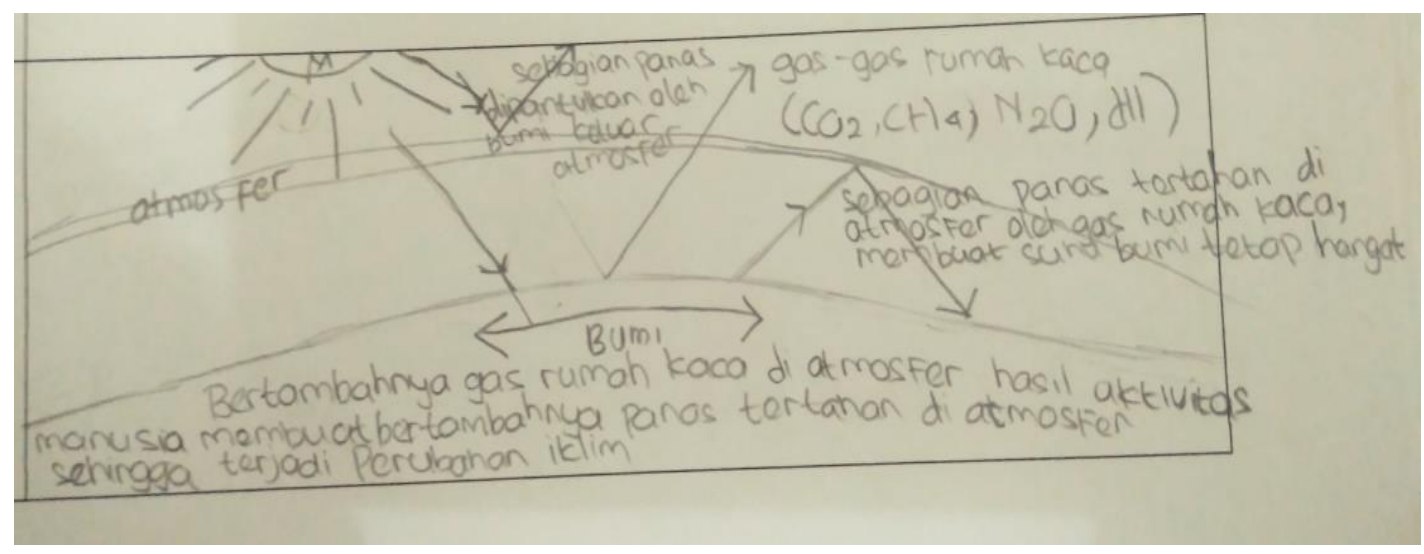

Figure 2. Example student illustrations were describing greenhouse gases as a layer in the atmosphere and radiative energy as "sun rays."

\subsubsection{The global warming impacts}

Based on data analysis, there are six segments of the global warming impacts, ocean, soil, air, plants and animals, humans, and weather and season changes (table 2).

Table 2. The impact of global warming

\begin{tabular}{lll}
\hline Impacts factors & Number of responses & \% of the total \\
\hline Ocean & 105 & 77.78 \\
Soil & 71 & 52.59 \\
Air & 99 & 73.33 \\
Plants and animals & 97 & 71.85 \\
Human & 82 & 60.74 \\
Weather and season changes & 93 & 68.89 \\
\hline
\end{tabular}

The majority of students responded ( $N=105,77.78 \%)$ that the impact of global warming is raising sea levels by the melting polar ice. The student believed that oceans absorbed a large portion of the sun's incoming energy that contributes as a significant operator of climate and weather through evaporation and convection. Some participants convinced that the reflected solar radiation back to Earth absorbed into the oceans does the seas warm and make this place into carbon garbage that pollutes the marine ecosystem. Changes in seawater temperature and density further affect the disruption of aquatic ecosystems or ocean life, such as damaged coral reefs, seaweed, and disturb the food chain of marine animals.

"The melting polar ice raises sea levels, increase sea temperature caused a lot of inert coral reefs" (P1S31-3).

"Increasing sea temperature disturbs the marine ecosystem like seaweed and coral reefs" (B1-S20-3). 
"Rising sea temperatures disturb the food chain because many sea mammals die" (J1-S7-3).

A total of $71(52.59 \%)$ students responded that the global warming impact on the soil. They expressed that the land becomes dry since water evaporates fast, and it is a significant cause of the drought. Besides, carbon dioxide from the atmosphere contaminated the land, where high levels of carbon dioxide absorbed the effect on fertility, and the soil becomes barren.

"Hot air temperatures make the dry soil due in no small amount of evaporation" (J1-S1-3).

"Carbon dioxide reduces soil fertility" (P1-S37-3).

More than $73 \%(\mathrm{~N}=99)$ of the participant also recognized that the impact of global warming is air pollution and hot air. Some of the participants remarked that the air becomes dirtier since there is a lot of flying dust, lots of carbon dioxide, carbon monoxide, methane, and other hazardous gases. Also, the rising air temperature causes tornadoes or storms.

"Hot air produces many storms" (J1-S17-3).

"Increasing concentration of carbon dioxide caused air pollution" (B1-S39-3).

Furthermore, overwhelmingly learner ( $N=97,71.85 \%)$ remarked that global warming increases the risk of plant and animal survival, and decrease in number. They reasoned that plants and animals would decrease in number because the amount of water decreases due to evaporation and drought. Some animals also would die because of lost their habitat, such as forest fires. The most interesting from student response was they described the impact on agriculture, crops, and livestock on human life by obstructing the food stocks. The changing of the weather diminished agricultural yields and harvest failures. Some students responded that the most remarkable thing for farmers in Indonesia is the initial information coming off the dry and rainy seasons. Global warming impacts a shift in the length and season period that causes crop failure.

"Extreme rainfall changes are affecting rice cropping patterns" (P1-S30-3).

"failed harvest, damaged rice plants will disrupt people's food stocks" (B1-S22-3).

Two students answered that the broader impacts of global warming also risk human health, food preservation, economic development, natural resource management, and infrastructure. Global warming disrupts the economy of society. Many infrastructures, such as bridges and buildings, are also easily damaged due to changing temperatures and weather.

"Increasing the sunlight intensity risked human health like skin cancer" (B1-S13-3).

"Changing weather makes the building such as bridge and road easily scratched" (J1-S28-3).

\subsubsection{Student answer model of cause and impact of global warming}

Based on students' responded, we present a comprehensive model of student answer on global warming. We noticed that individual students might hold a different model that involved different conceptual focus. However, the similarities among the student answer provide confidence to build a general student answer model of the climate system. This model assists as a starting point and frame in explaining and conceptualizing seventh-grade students' cognition on the climate system.

The model appeared that students ultimately believed that the cause of global warming is due to human activities, which finally have an impact on humans themselves. Humans and nature are closely related. The contribution of human activities increased air pollution and greenhouse gas concentrations in the atmosphere.The student thinking about the climate system is substantially linear. For example, burning fossil fuels and forest fires increase air pollution and greenhouse gases, which causes global warming, which interferes with animals, plants, and humans survivals. 


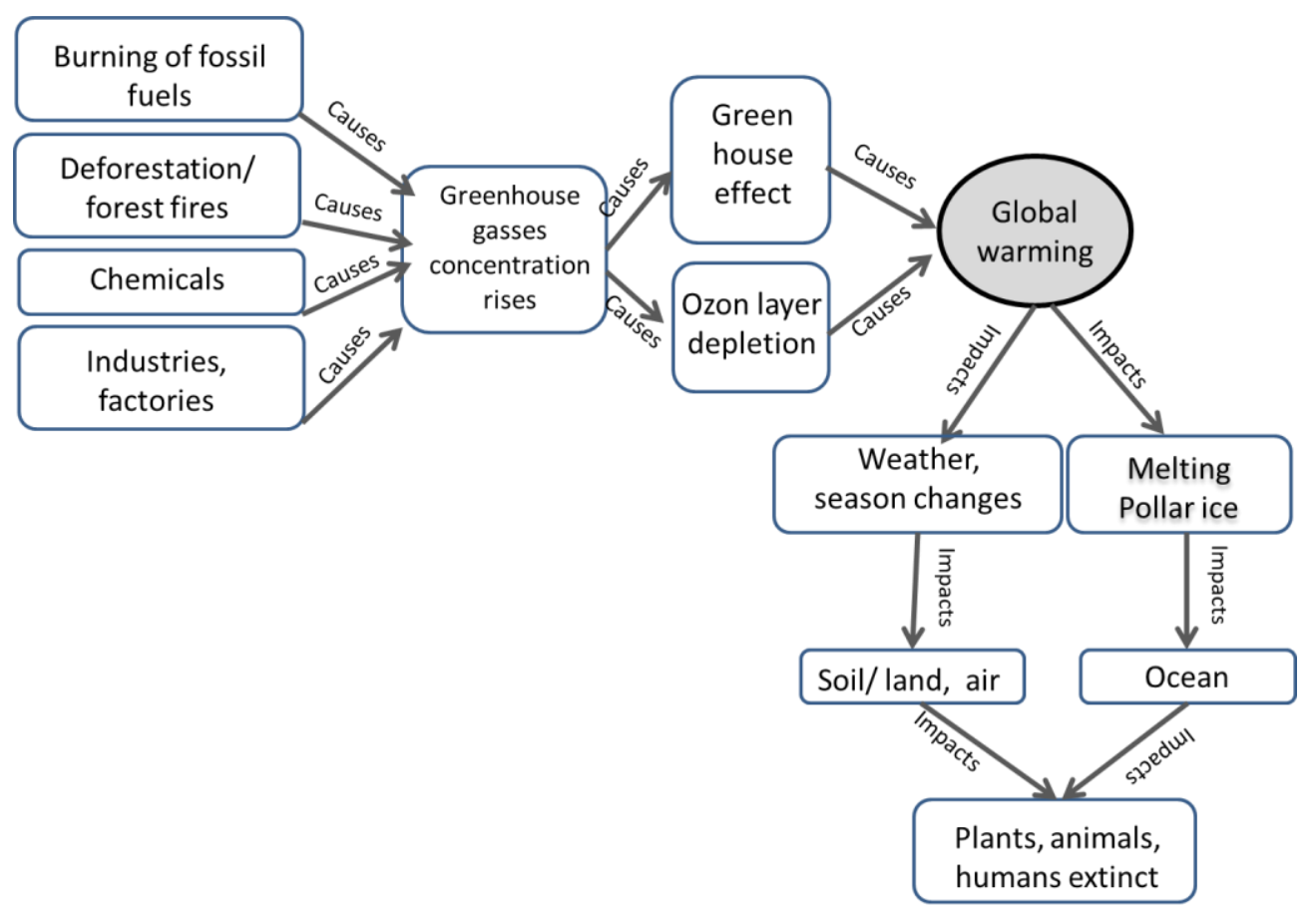

Figure 3. Seventh-grade student answer model

\subsection{Discussion}

The results of the analysis showed that students indicated the causes of global warming were six factors: burning of fossil fuels, greenhouse effect, ozone layer depletion, deforestation and forest fire, chemicals, industries/factories. Burning of fossil fuels, deforestation, and forest fires, chemicals, and industries/factories are the main factors that cause an increase in the concentration of greenhouse gases such as $\mathrm{CO} 2, \mathrm{CH} 4, \mathrm{CFC}$ in the atmosphere, which affects the greenhouse effect and ozone layer depletion. The participant conceded that global warming as being driven by the greenhouse effect and ozone layer depletion. In this case, students have a misconception where the depletion of the ozone layer is indicated as a cause of global warming. They believed that the ozone depletion caused the intensity of sunlight entering the earth to rise and make the earth's temperature increases. Several studies (e.g., Andersson \& Wallin, 2000; Pruneau, Gravel, Bourque, \& Langis, 2003; Shepardson et al., 2009, 2012; Tolppanen \& Aksela, 2018) also have shown that the misconception that occurred in students is the ozone layer depletion caused global warming and climate change. Andersson and Wallin (2000) showed that the amount of greenhouse gas concentrations, primarily carbon dioxide is the leading cause of global warming. These greenhouse gases trap sunlight in the atmosphere and reflect the energy in the form of short waves/ infrared (Andersson \& Wallin, 2000; Koulaidis \& Christidou, 1999; Pruneau, Gravel, Bourque, \& Langis, 2003).

Furthermore, the student cognition about the impact of global warming believed that plants, animals, and humans would be extinct or diminish in number as an effect of warmer weather, heat, flood, and drought conditions. They also concerned the impact on agriculture and infrastructure. Like a previous study (e.g., Shepardson et al., 2009), the students thought that global warming would only impact temperature, melting polar ice, and local weather. In essence, the participants hold a pure cognition on the climate system concepts. They did not recognize that global warming force impact differently in various regions in the world. In short, they only focused on the regional aspect of the climate system than global. Nevertheless, the student had a strong foundation for environmental concern that causes and effect on the global climate system because of harmful human activities.

The model showed that changes in human behavior become the fundamental element in mitigation and adaptation efforts. The human activities are expected to increase to the natural greenhouse effect, 
rising global warming. The primary effects of human actions result from industries/factories pollution and fossil fuel usage, which have begun to a build-up of carbon dioxide and other greenhouse gas concentration in the atmosphere, and deforestation, which has emerged in the loss of carbon sinks that separate carbon naturally (Rajeev Gowda et al., 1997). People must begin to realize and be awakened to understand the impact of global warming on environmental problems, both locally and globally. This awareness must be accompanied by knowledge, expertise, attitude, and participation in protecting the surroundings. Human activities would change to the system of the climate system. The critical areas of climate change need to develop their knowledge of the complex interaction between humans and their ecosystems (Inaotombi \& Mahanta, 2018). Environmental education and education for sustainable development provide a framework for implementing climate change education. Educating students regarding climate system is a challenge to science and environmental educators since this issue interdisciplinarity and complexity. The successful implementation of the topic of climate change requires creativity educators to formulate and manage methods of learning.

\section{Conclusion}

Climate change as a change in the composition of the global atmosphere and natural climate variability in a comparable time affected by human activities either directly or indirectly. Students indicated the causes of global warming were six factors: burning of fossil fuels, greenhouse effect, ozone layer depletion, deforestation and forest fire, chemicals, industries/factories. The student cognition about the impact of global warming also believed that plants, animals, and humans would be extinct or diminish in number. The student thinking about the climate system is substantially linear. They only focused on the regional aspect of the climate system than global. Furthermore, there is a need to recognize the relationship between learner cognition and their behaviors. Also, there is a need for future research to investigate the student individual conceptual models and how social interaction influences student cognition about the climate system. These might paint a broader and more precise picture of the role that students also play in resolving the future climate system.

\section{References}

Andersson, B., \& Wallin, A. (2000). Students' understanding of the greenhouse effect, the societal consequences of reducing $\mathrm{CO} 2$ emissions and the problem of ozone layer depletion. Journal of Research in Science Teaching, 37(10), 1096-1111. https://doi.org/10.1002/10982736(200012)37:10<1096::AID-TEA4>3.0.CO;2-8

Bélanger, P. (2003). Learning environments and environmental education. New Directions for Adult and Continuing Education, 2003(99), 79-88. https://doi.org/10.1002/ace.112

Calderon, J. L. (2011). How-to data collection series: The evolution of the focused discussion group--from non-participant to one of the crew. Qualitative Report, 16(1), 308-311. Retrieved from http://login.ezproxy.library.ualberta.ca/login?url=http://search.ebscohost.com/login.aspx?direct=tru e\&db=eric\&AN=EJ914051\&site=eds-live\&scope=site

Creswell, J. W. (2012). Educational research: Planning, conducting, and evaluating quantitative and qualitative research (4th ed.). Boston: Pearson Education, Inc.

Dewi, J. K., Hendarti, L., Matakupan, S., \& Lisdiyanta, T. (2012). Suplemen Pembelajaran Perubahan Iklim untuk Guru (Climate Change Learning Supplements for Teachers). Jakarta: Kementeran Lingungan Hidup.

Global Education Monitoring. (2016). Pendidikan bagi manusia dan bumi : France.

Inaotombi, S., \& Mahanta, P. C. (2018). Pathways of socio-ecological resilience to climate change for fisheries through indigenous knowledge. Human and Ecological Risk Assessment: An International Journal, 24, 1-13. https://doi.org/10.1080/10807039.2018.1482197

Johnson, R. B., \& Christensen, L. B. (2013). Educational research: Quantitative, qualitative, and mixed approaches (5 edition). Thousand Oaks, Calif: SAGE Publications, Inc. 
Koulaidis, V., \& Christidou, V. (1999). Models of students' thinking concerning the greenhouse effect and teaching implications. Science Education, 83(5), 559-576. https://doi.org/10.1002/(SICI)1098237X(199909)83:5<559::AID-SCE4>3.0.CO;2-E

Kress, G. R., Jewitt, C., Ogborn, J., \& Tsatsarelis, C. (2014). Multimodal teaching and learning: the rhetorics of the science classroom. London: Bloomsbury. Retrieved from https://books.google.co.id/books/about/Multimodal_Teaching_and_Learning.html?id=2QxCBAAAQB AJ\&redir_esc $=\mathrm{y}$

Ocal, A., Kisoglu, M., Alas, A., \& Gurbuz, H. (2011). Turkish prospective teachers' understanding and misunderstanding on global warming. International Research in Geographical and Environmental Education, 20(3), 215-226. https://doi.org/10.1080/10382046.2011.588504

Österlind, K. (2005). Concept formation in environmental education: 14-year olds' work on the intensified greenhouse effect and the depletion of the ozone layer. International Journal of Science Education, 27(8), 891-908. https://doi.org/10.1080/09500690500038264

Papadimitriou, V. (2004). Prospective primary teachers' understanding of climate change, greenhouse effect, and ozone layer depletion. Journal of Science Education and Technology, 13(2), 299-307. https://doi.org/10.1023/B:JOST.0000031268.72848.6d

Pruneau, D., Gravel, H., Bourque, W., \& Langis, J. (2003). Experimentation with a socio-constructivist process for climate change education. Environmental Education Research, 9(4), 429-446. https://doi.org/10.1080/1350462032000126096

Rajeev Gowda, M. V., Fox, J. C., Magelky, R. D., Gowda, M. V. R., Fox, J. C., \& Magelky, R. D. (1997). Students' Understanding of Climate Change: Insights for Scientists and Educators. Bulletin of the American Meteorological Society, 78(10), 2232-2240. https://doi.org/10.1175/1520-047778.10 .2232

Schreiner, C., Henriksen, E. K., \& Kirkeby Hansen, P. J. (2005). Climate Education: Empowering Today's Youth to Meet Tomorrow's Challenges. Studies in Science Education, 41(1), 3-49. https://doi.org/10.1080/03057260508560213

Serafin, R., Heikes, B., Sargeant, D., Smith, W., Takle, E., \& Wakimoto, R. (1991). Study on observational systems: A review of meteorological and oceanographic education in observational techniques and the relationship to national facilities and needs. Bulletin of the American Meteorological Society. Retrieved from https://lib.dr.iastate.edu/ge_at_pubs/206

Shepardson, D. P., Niyogi, D., Choi, S., \& Charusombat, U. (2009). Seventh grade students' conceptions of global warming and climate change. Environmental Education Research, 15(5), 549-570. https://doi.org/10.1080/13504620903114592

Shepardson, D. P., Niyogi, D., Roychoudhury, A., \& Hirsch, A. (2012). Conceptualizing climate change in the context of a climate system: implications for climate and environmental education. Environmental Education Research, 18(3), 323-352. https://doi.org/10.1080/13504622.2011.622839

Stevenson, R. B. (2007). Schooling and environmental/sustainability education: from discourses of policy and practice to discourses of professional learning. Environmental Education Research, 13(2), 265285. https://doi.org/10.1080/13504620701295650

Svihla, V., \& Linn, M. C. (2012). A Design-based approach to fostering understanding of global climate change. International Journal of Science Education, 34(5), 651-676. https://doi.org/10.1080/09500693.2011.597453

Tolppanen, S., \& Aksela, M. (2018). Identifying and addressing students' questions on climate change. The Journal of Environmental Education, 49(5), 375-389. https://doi.org/10.1080/00958964.2017.1417816 